\title{
Sulfate pollution: evidence for electrochemical production of persulfate by oxidizing sulfate released by the surfactant sodium dodecyl sulfate
}

\author{
Karla C. de F. Araújo ${ }^{1}$. Jéssica P. de P. Barreto ${ }^{1}$. Jussara C. Cardozo ${ }^{1}$. Elisama Vieira dos Santos ${ }^{1}$. \\ Danyelle M. de Araújo ${ }^{1}$. Carlos A. Martínez-Huitle ${ }^{1,2}$
}

Received: 17 August 2017 / Accepted: 29 December 2017 / Published online: 13 January 2018

c) Springer International Publishing AG, part of Springer Nature 2018

\begin{abstract}
There is increasing concern about contamination by surfactants that are used to extract organic pollutants during remediation of polluted soils and aquifers. For instance, the surfactant sodium dodecyl sulfate may produce sulfate, which is a pollutant at high concentrations. Reports suggest that when remediation involves sodium dodecyl sulfate and electrochemical treatments, $\mathrm{SO}_{4}^{2-}$ ions could be produced then oxidized to persulfate $\left(\mathrm{S}_{2} \mathrm{O}_{8}^{2-}\right)$. However, there is few knowledge on the mechanism of electrochemical production of sulfate and persulfate. Here, we tested for first time the electrochemical production of persulfate from sulfate released by oxidation of sodium dodecyl sulfate, using anodic oxidation with boron-doped diamond. Results show a high efficiency of persulfate production, reaching $2.5 \mu \mathrm{M}$, when $500 \mathrm{mg} / \mathrm{L}$ of surfactant in $0.05 \mathrm{~mol} / \mathrm{L}$ of $\mathrm{Na}_{2} \mathrm{SO}_{4}$ was electrolyzed at $60 \mathrm{~mA} \mathrm{~cm}{ }^{-2}$, by comparison with only $0.7 \mu \mathrm{M}$ of persulfate without surfactant in solution. This efficiency is explained by electrogeneration of hydroxyl radicals and persulfate. Results also show that $97 \%$ of the surfactant is transformed by fragmentation and oxidation, as revealed by particle size measurements.
\end{abstract}

Keywords Persulfate $\cdot$ Diamond electrode $\cdot$ Surfactant $\cdot$ Sodium dodecyl sulfate $\cdot$ Sulfate release

\section{Introduction}

In the last years, electrochemical advanced oxidation processes have received great attention for the scientific community as innovative alternatives for treating different wastewaters containing with toxic and dangerous organic compounds. Among electrochemical advanced oxidation processes, the electrochemical oxidation is one of the most used technologies for removing organic from water, wastewater and soil as well as to produce electrochemically strong oxidant species. The electrochemical oxidation process is based on the preferential use of anodic materials of high over-potential of oxygen evolution that yield ${ }^{\circ} \mathrm{OH}$ as

Carlos A. Martínez-Huitle carlosmh@quimica.ufrn.br

1 Institute of Chemistry, Federal University of Rio Grande do Norte, Lagoa Nova, Natal, RN CEP 59078-970, Brazil

2 National Institute for Alternative Technologies of Detection, Toxicological Evaluation and Removal of Micropollutants and Radioactives (INCT-DATREM), Institute of Chemistry, Unesp, P.O. Box 355, Araraquara, SP 14800-900, Brazil intermediate of the water oxidation from reaction (1) instead of releasing oxygen from reaction (2):

$\mathrm{M}+\mathrm{H}_{2} \mathrm{O} \rightarrow \mathrm{M}(\mathrm{OH})+\mathrm{H}^{+}+\mathrm{e}^{-}$

$\mathrm{H}_{2} \mathrm{O} \rightarrow 1 / 2 \mathrm{O}_{2}+2 \mathrm{H}^{+}+2 \mathrm{e}^{-}$

where $\mathrm{M}(\cdot \mathrm{OH})$ represents the adsorbed $\cdot \mathrm{OH}$ (chemically or physically) onto the anode surface $\mathrm{M}$. Thus, the electrogenerated $\cdot \mathrm{OH}$ acts as mediator on the mineralization of organic pollutants.

Boron-doped diamond electrodes are widely studied and applied in electrochemical oxidation because these can promote the best degradation results of organic pollutants in water due to the high amount of $\cdot \mathrm{OH}$ radicals produced, which are physically adsorbed on surface (boron-doped diamond $(\cdot \mathrm{OH})$ ) compared with other anodes. Boron-doped diamond also produces electrochemically different oxidizing agents, such as active chlorine, ozone, hydrogen peroxide and persulfate.

Persulfate $\left(\mathrm{S}_{2} \mathrm{O}_{8}^{2-}\right)$ is considered a strong oxidant with a reduction potential $\left(\mathrm{E}^{\circ}\right)$ of $2.1 \mathrm{~V}$, which is greater than the value for other oxidants such as $\mathrm{H}_{2} \mathrm{O}_{2}\left(\mathrm{E}^{\circ}=1.8 \mathrm{~V}\right)$ 
and permanganate $\left(\mathrm{MnO}_{4}^{-}\right)\left(\mathrm{E}^{\circ}=1.7 \mathrm{~V}\right)$ (Araújo et al. 2015). Therefore, many works have been published in recent years about the use of this oxidant for soil and water remediation (Chen and Su 2012; Xie et al. 2014; Fan et al. 2015; Budaev et al. 2015).

Persulfate can be electrochemically produced via borondoped diamond electrolysis in the presence of sulfate ions in solution by direct or indirect mechanisms (Michaud et al. 2000; Davis et al. 2014). Alternatively, the formation of persulfate is also feasible when the sulfate ion is released in solution after an initial oxidation reaction. For example, some azo dyes with sulfate in their chemical structure release sulfate ions after their oxidation (Brillas and Martínez-Huitle 2015). In recent years, similar behavior has been reported (Santos et al. 2015a, b; Bandala et al. 2007; Liang et al. 2008) when wastewaters containing sodium dodecyl sulfate were electrolyzed, and consequently, the production of persulfate from sulfate ions in solution due to the degradation of sodium dodecyl sulfate was proposed. However, no works have been published yet demonstrating this improvement. Here, we present the enhancement, for first time, on the electrochemical production of persulfate by using diamond electrodes when sodium dodecyl sulfate is present in solution.

\section{Experimental}

\section{Materials and chemicals}

The water was obtained from purified water system (MilliQ system, with resistivity $\geq 18 \mathrm{M} \Omega \mathrm{cm}$ at $25^{\circ} \mathrm{C}$ ). Sodium dodecyl sulfate (Aldrich), $\mathrm{Na}_{2} \mathrm{SO}_{4}$ (Aldrich), chloroform $\left(\mathrm{CHCl}_{3}\right.$, P.A. by Panreac), sodium tetraborate and methylene blue were purchased from chemical companies.

\section{Electrolysis for persulfate electrosynthesis}

Electrolysis of $1 \mathrm{~L}$ of synthetic solution containing with $0.0017 \mathrm{M}(500 \mathrm{mg} / \mathrm{L})$ of sodium dodecyl sulfate in $\mathrm{Na}_{2} \mathrm{SO}_{4}$ as supporting electrolyte $(0.025$ or $0.05 \mathrm{~mol} / \mathrm{L})$ was performed by applying 15,30 and $60 \mathrm{~mA} \mathrm{~cm}^{-2}$ for $360 \mathrm{~min}$ in an undivided electrochemical cell in continuous flow. $\mathrm{Nb}$-/boron-doped diamond and $\mathrm{Ti}$ were used as anode and cathode, respectively, with an area of $63.6 \mathrm{~cm}^{2}$ (disk plates). The gap distance between electrodes was ca. $1 \mathrm{~cm}$. Through the sample solutions, collected in predetermined time interval, were obtained the concentration profiles of $\mathrm{S}_{2} \mathrm{O}_{8}^{2-}$ for each one of the synthetic solutions electrolyzed.

\section{Persulfate and sodium dodecyl sulfate determination}

For monitoring production of persulfate at boron-doped diamond electrolysis, aliquots of 200 microliters were analyzed by using in situ chemical oxidation method (Liang et al. 2008) from 190 to $600 \mathrm{~nm}$ with a Shimadzu spectrophotometer model 1800. A simplified spectrophotometric method for determining sodium dodecyl sulfate concentration, based on the formation of the ionic pair anionic surfactant-methylene blue, was used (Jurado et al. 2006).

\section{Particle size and z-potential}

To determine the micelle surface charge, the z-potential of several samples obtained from the electrolysis was measured using Zetasizer Nano analyzer (Malvern). It was equipped with a MPT-2 automatic titrator. The z-potential determination uses the Laser Doppler Electrophoresis technology. The movement of charged particles in an electric field is measured through the Doppler effect. The light dispersed by a moving particle undergoes a frequency change as a consequence of its relative rate. As the frequency of the light is high $\left(10^{14} \mathrm{~Hz}\right)$, the change in the frequency only can be measured using an interferometric technique. One of the light beams must pass through the particle (dispersed beam), and the other light beam is guided around the cell. By comparing the frequency of both beams in any point after dispersed beam has crossed the sample, the mobility of the particles under the influence of an electrical field is measured. The particle size was monitored during electrochemical oxidation with a Mastersizerhydro 2000SM (Malvern). It measures scattered light energy versus angle for samples of unknown size distribution. An optical model can predict the scattering pattern (scattered light energy versus angle) given a known particle size distribution.

\section{Chemical oxygen demand removal}

Decontamination of effluent was monitored from the abatement of its chemical oxygen demand (COD). Values were obtained, using a HANNA HI 83099 spectrophotometer after digestion of samples in a HANNA thermo-reactor. From these data, the percentage of chemical oxygen demand decay was estimated from the following equation:

$\% \mathrm{COD}$ removal $=\left[\left(\mathrm{COD}_{0}-\mathrm{COD}_{\mathrm{f}}\right) / \mathrm{COD}_{0}\right] \times 100$

where $\mathrm{COD}_{0}$ and $\mathrm{COD}_{\mathrm{f}}$ represent the values before and at the end of the electrolysis, respectively. 


\section{Results and discussion}

\section{Electrochemical production of persulfate in the absence or presence of surfactant}

Figure 1 compares the production of persulfate as a function of applied current density and time in the absence or in the presence of sodium dodecyl sulfate in solution as well as the effect of sulfate concentration. As can be observed in Fig. 1a, a lower $\mathrm{S}_{2} \mathrm{O}_{8}^{2-}$ concentration is produced by applying
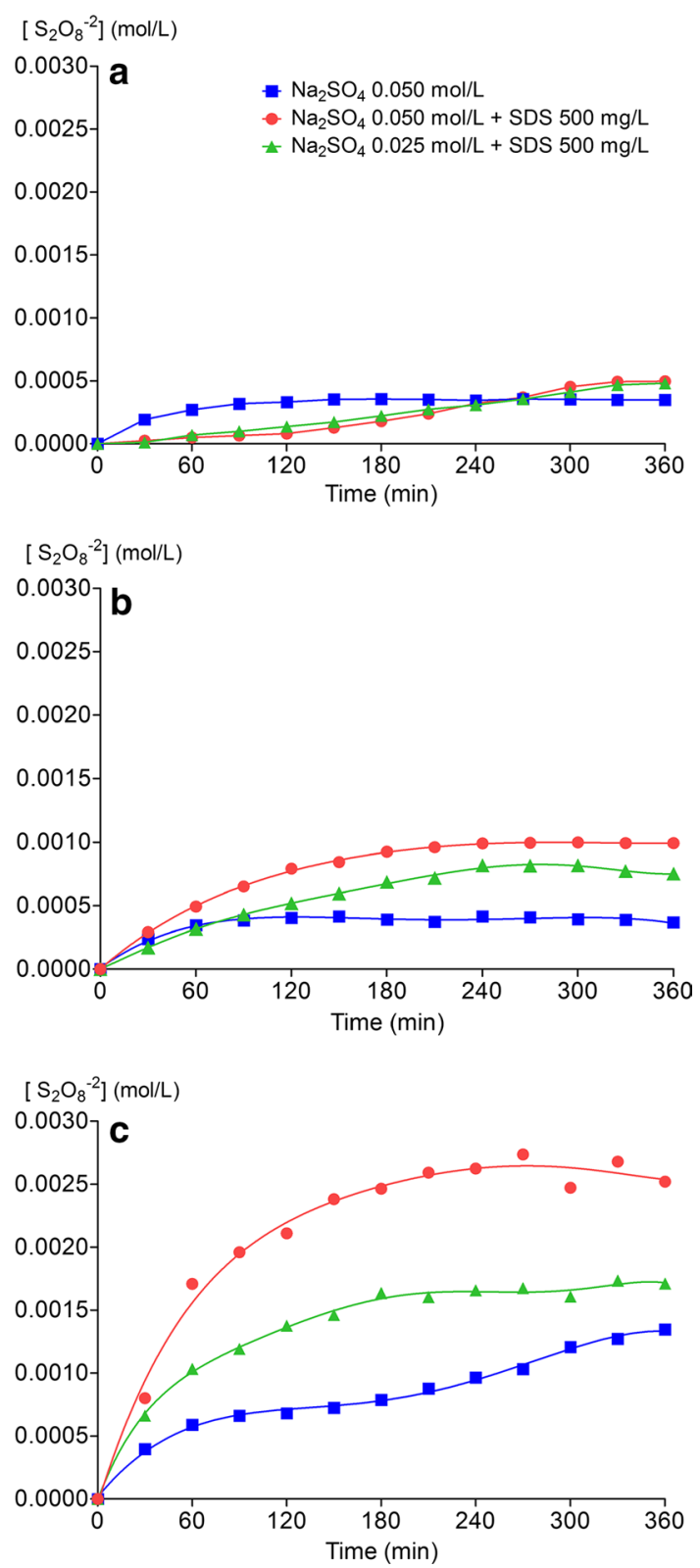

Fig. 1 Electrochemical production of persulfate, as a function of applied current density (a 15, b 30, c $60 \mathrm{~mA} \mathrm{~cm}^{-2}$ ) and time, in the absence and in the presence of surfactant in solution. Sodium dodecyl sulfate (SDS)
$15 \mathrm{~mA} \mathrm{~cm}{ }^{-2}$ in $0.05 \mathrm{~mol} / \mathrm{L}$ of $\mathrm{Na}_{2} \mathrm{SO}_{4}$, achieving a plateau production after $60 \mathrm{~min}$ of electrolysis. Conversely, at and 30 and $60 \mathrm{~mA} \mathrm{~cm}^{-2}$ (Fig. 1b, c), a significant increase on the production of $\mathrm{S}_{2} \mathrm{O}_{8}^{2-}$ was achieved. This behavior can be explained for indirect oxidation process in sulfate aqueous solutions (in the absence of sodium dodecyl sulfate), where an enough amount of reactive boron-doped diamond $(\cdot \mathrm{OH})$ is produced at higher applied current densities, which causes a sequence of reactions (Eqs. (4-6)) that are responsible for the formation of $\mathrm{S}_{2} \mathrm{O}_{8}^{2-}$ (Serrano et al. 2002; Cañizares et al. 2008);

$2 \mathrm{SO}_{4}^{2-} \rightarrow \mathrm{S}_{2} \mathrm{O}_{8}^{2-}+2 \mathrm{e}^{-}$

boron-doped diamond $(\cdot \mathrm{OH})+\mathrm{SO}_{4}^{2-}$

$\rightarrow$ boron-doped diamond $\left(\mathrm{SO}_{4}^{--}\right)+\mathrm{OH}^{-}$

boron-doped diamond $\left(\mathrm{SO}_{4}^{-\cdot}\right)+\mathrm{SO}_{4}^{2-} \rightarrow \mathrm{S}_{2} \mathrm{O}_{8}^{2-}+e^{-}$

When a known concentration of sodium dodecyl sulfate $(0.0017 \mathrm{~mol} / \mathrm{L} \approx 500 \mathrm{mg} / \mathrm{L})$ was added to the solution, an increase on the $\mathrm{S}_{2} \mathrm{O}_{8}^{2-}$ was achieved, as a function of applied current density, in comparison with the results obtained in the absence of sodium dodecyl sulfate. At $15 \mathrm{~mA} \mathrm{~cm}^{-2}$, a low $\mathrm{S}_{2} \mathrm{O}_{8}^{2-}$ production is attained before $200 \mathrm{~min}$ (Fig. 1a). It could be due to the reaction of ${ }^{\circ} \mathrm{OH}$ radicals with sodium dodecyl sulfate molecules, avoiding the reactions (5) and (6) in the beginning of the electrolysis, and consequently, producing lower concentration of persulfate. Conversely, at $30 \mathrm{~mA} \mathrm{~cm}^{-2}$, an increase on the production of $\mathrm{S}_{2} \mathrm{O}_{8}^{2-}$ is achieved in the beginning of the boron-doped diamond electrolysis, increasing gradually up to $300 \mathrm{~min}$. Under these experimental conditions, a higher amount of ${ }^{\circ} \mathrm{OH}$ radicals and $\mathrm{S}_{2} \mathrm{O}_{8}^{2-}$ is produced in solution, contributing with the degradation of sodium dodecyl sulfate to promote the sulfate release (Eq. 7). Subsequently, $\mathrm{SO}_{4}^{2-}$ is oxidized to $\mathrm{S}_{2} \mathrm{O}_{8}^{2-}$ again (Eq. (4-6)), increasing its concentration in solution (Eq. 6).

sodium dodecyl sulfate $\stackrel{\text { [oxidants }=\cdot \mathrm{OH} \text { and } \mathrm{S}_{2} \mathrm{O}_{8}^{2-} \text { ] }}{\longrightarrow} \mathrm{SO}_{4}^{2-} \rightarrow \mathrm{S}_{2} \mathrm{O}_{8}^{2-}$

Meanwhile, at $60 \mathrm{~mA} \mathrm{~cm}^{-2}$, a substantial increase on the production $\mathrm{S}_{2} \mathrm{O}_{8}^{2-}$ was obtained, when sodium dodecyl sulfate was added $(500 \mathrm{mg} / \mathrm{L})$. This significant increase could be explained by the rapid degradation of sodium dodecyl sulfate via ${ }^{\circ} \mathrm{OH}$ radicals and $\mathrm{S}_{2} \mathrm{O}_{8}^{2-}$ (from $\mathrm{SO}_{4}^{2-}$ in solution) favoring the release of $\mathrm{SO}_{4}^{2-}$ in solution (Eq. (7)) and producing more $\mathrm{S}_{2} \mathrm{O}_{8}^{2-}$, as hypothesized by Santos and coworkers (Santos et al. 2015a, b). Another important feature is that the concentration of $\mathrm{SO}_{4}^{2-}$ from sodium dodecyl sulfate degradation seems to be the responsible about the increase on the persulfate production. The results clearly showed that a decrease on the concentration of sodium sulfate (from 0.05 
to $0.025 \mathrm{~mol} / \mathrm{L}$ ) can be sufficient for a high production of $\mathrm{S}_{2} \mathrm{O}_{8}^{2-}$, especially when higher applied current density is used. However, several mechanisms seem to be present during the electrolysis in the presence of sodium dodecyl sulfate because sodium dodecyl sulfate had a significant effect on the production of persulfate when the amount of sulfate from sodium dodecyl sulfate would be much lower than that of supporting electrolyte. In fact, it can be observed, at 30 and $60 \mathrm{~mA} \mathrm{~cm}^{-2}$ (Fig. 1b, c), when the concentration of persulfate had a significant increase after a decrease on the sulfate concentration maintaining sodium dodecyl sulfate amount in solution.

\section{Micelle formation and particle size behavior}

Although the mechanism in Eq. 7 seems feasible, independently of $\mathrm{SO}_{4}^{2-}$ concentration, the formation of micelles or not in solution would be confirmed to understand the production of $\mathrm{S}_{2} \mathrm{O}_{8}^{2-}$ from the release of $\mathrm{SO}_{4}^{2-}$. In order to confirm that critical micellar concentration was determined by using solutions of $0.05 \mathrm{~mol} / \mathrm{L}$ of $\mathrm{Na}_{2} \mathrm{SO}_{4}(1 \mathrm{~L})$ and $3 \%$ of sodium dodecyl sulfate in $30 \mathrm{~mL}$ at $25{ }^{\circ} \mathrm{C}$ in order to measure the superficial tension (Fig. 2a). From the results obtained, the critical micellar concentration was about $198 \mathrm{mg} / \mathrm{L}$; then, at higher sodium dodecyl sulfate concentrations, the formation of spherical aggregates, called micelles, is achieved. This aspect is of great importance, because the surfactants, when in the form of micelles, have different behavior of the free monomers in solution. According the literature (Holmberg et al. 2002; Maniasso 2001) in a micelle, the hydrophobic tails of several surfactant molecules assemble into a core, the most stable form of which having no contact with water. In our case, at $500 \mathrm{mg} / \mathrm{L}$, the sulfate hydrophilic heads of sodium dodecyl sulfate are in contact with water/ sulfate solution, then, these aggregates are easily fragmented by ${ }^{\circ} \mathrm{OH}$ radicals and persulfate (Eq. 7). After that $\mathrm{SO}_{4}^{2-}$ is released in solution, contributing with persulfate formation again. Taking into consideration the above information, the behavior of the sodium dodecyl sulfate-micelle particle during the electrolysis was investigated, then, a particle size distribution from electrolyzed samples was determined in order to estimate the mean dimension of micelles in solution. Figure $2 b$ shows the behavior of particle size and $z$-potential, as a function of time during the electrolysis of $500 \mathrm{mg} / \mathrm{L}$ of sodium dodecyl sulfate in $0.05 \mathrm{~mol} / \mathrm{L}$ of $\mathrm{Na}_{2} \mathrm{SO}_{4}$ by applying $60 \mathrm{~mA} \mathrm{~cm}^{-2}$. As can be observed, the size of particles is higher and the superficial charge is more negative. In fact, in the beginning of the electrolysis, higher micelles can be formed due to the higher concentration of sodium dodecyl sulfate present in solution according its critical micellar concentration, after that, the particle size suffers a depletion as a function of the electrolysis time. This behavior is related to the number of sodium dodecyl sulfate molecules forming the micelles. Meanwhile, the effective charge of the particles is also altered, passing from negative to more positive (Fig. 2b). These figures indicate that the surfactant micelles are drastically attacked during the first stages to form smaller particles with more negative surface charge. In this point, it is important to take in mind that it is used an anionic surfactant and thus, the expected superficial charge of micelles is negative. After this initial rapid reduction in size of the particles, size continues decreasing till the end of the test, although at a lower rate (Fig. 2b). Then, the increase in the z-potential toward more positive values confirms that OH radicals and persulfate are produced by boron-doped diamond electrolysis; these strong oxidants promote the fragmentation of sodium dodecyl sulfate structure, resulting in a disaggregation packing density of sodium dodecyl sulfate and the release of sulfate hydrophilic heads, making the new smaller particles, more positive.
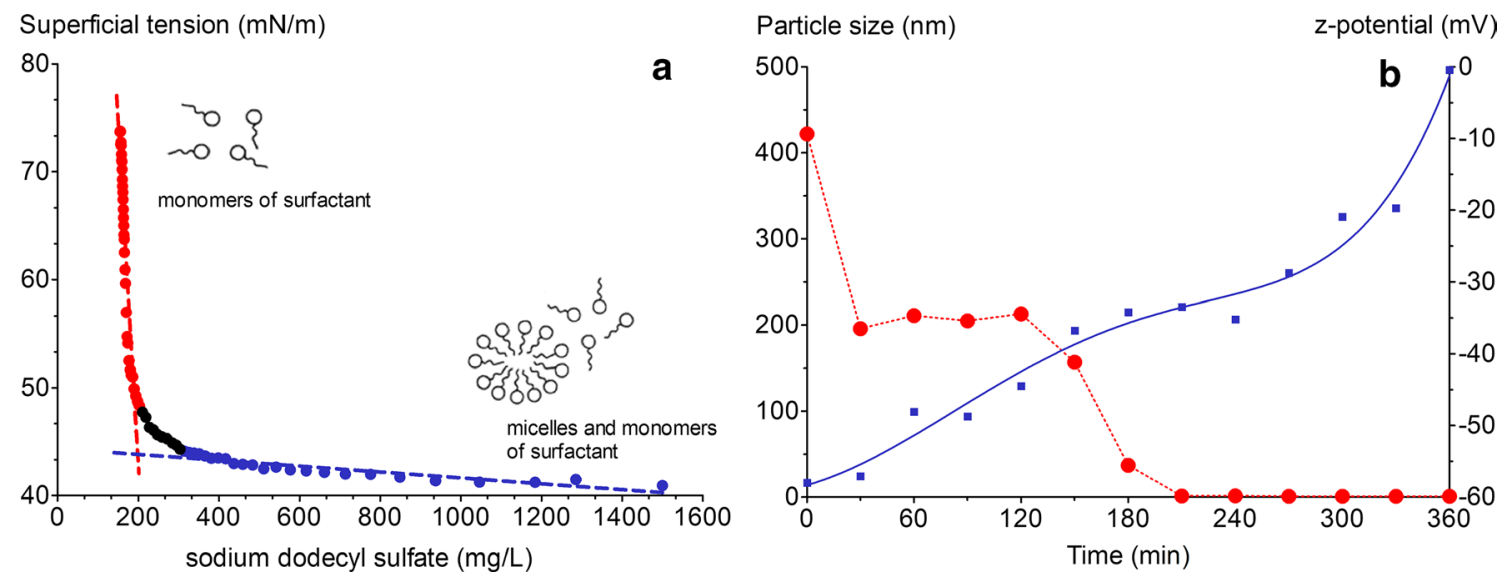

Fig. 2 Note the effect of the superficial tension as a function of sodium dodecyl sulfate concentration (a) as well as the particle size behavior and changes in the z-potential during the electrolysis of a solution of $500 \mathrm{mg} / \mathrm{L}$ of surfactant in $0.05 \mathrm{~mol} / \mathrm{L} \mathrm{of} \mathrm{Na}_{2} \mathrm{SO}_{4}$ at $60 \mathrm{~mA} \mathrm{~cm}^{-2}(\mathbf{b})$ 


\section{Surfactant degradation by anodic oxidation}

The last conclusions open new considerations about the use of sodium dodecyl sulfate as auxiliary reagent for remediation of soil and water because sodium dodecyl sulfate can remove the organic matter by extraction, flushing, soil-washing, water-micelles formation and after that, the new effluent is treated by boron-doped diamond electrolysis, producing $\mathrm{S}_{2} \mathrm{O}_{8}^{2-}$ from sodium dodecyl sulfate fragmentation. However, sodium dodecyl sulfate, itself, as a surfactant, is polluting; then, it is important to confirm its elimination when it is used. Figure 3 a shows chemical oxygen demand decay of a solution with $500 \mathrm{mg} / \mathrm{L}$ of sodium dodecyl sulfate and $0.05 \mathrm{~mol} / \mathrm{L}$ of $\mathrm{Na}_{2} \mathrm{SO}_{4}$ with boron-doped diamond electrolysis by applying 15,30 and $60 \mathrm{~mA} \mathrm{~cm}^{-2}$, obtaining removals of 80,96 and $98 \%$, respectively. These results clearly indicate that the sodium dodecyl sulfate can be also eliminated by oxidants produced electrochemically (Eq. 7) (Barreto et al. 2015). It can be also confirmed from the sodium dodecyl sulfate concentration decay under these conditions (Fig. 3b). However, the sodium dodecyl sulfate decay is very slow in the beginning (up to $120 \mathrm{~min}$ ), even if the chemical oxygen demand removal is rapidly achieved. This behavior can be related to the presence of a significant amount of micelles in solution, with high particle size (see Fig. 2b where mean size is $200 \mathrm{~nm}$ up to $120 \mathrm{~min}$, and after that, the particle size decreased), avoiding a rapid fragmentation of the main surfactant carbon chain. But, when an important amount of micelles is broken in minor carbon chains, the elimination is more substantial. As a final point, no complete elimination of organic matter (Fig. 3) after 420 min can be explained by the reaction of oxygen evolution, which competes with the formation of persulfate in aqueous solutions (Eq. (8)).

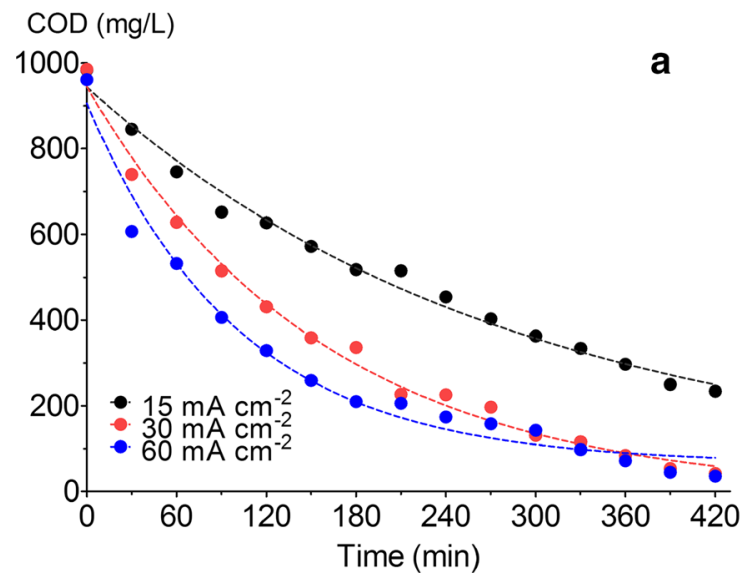

Fig. 3 Note the effect of the COD removal as a function of time as well as the surfactant concentration decay versus time during the oxidation of $500 \mathrm{mg} / \mathrm{L}$ of SDS in $0.05 \mathrm{~mol} / \mathrm{L}$ of $\mathrm{Na}_{2} \mathrm{SO}_{4}$ at different
$2 \cdot \mathrm{OH} \rightarrow \mathrm{O}_{2}+2 \mathrm{H}^{+}+2 \mathrm{e}^{-}$

\section{Conclusions}

These results indicated that the sodium dodecyl sulfate has influences on the electrosynthesis of $\mathrm{S}_{2} \mathrm{O}_{8}^{2-}$. The increase in concentration of persulfate suggests that the degradation of sodium dodecyl sulfate generates sulfate, which consequently produces persulfate (Fig. 4). Although several mechanisms seem to be present during electrolyzes

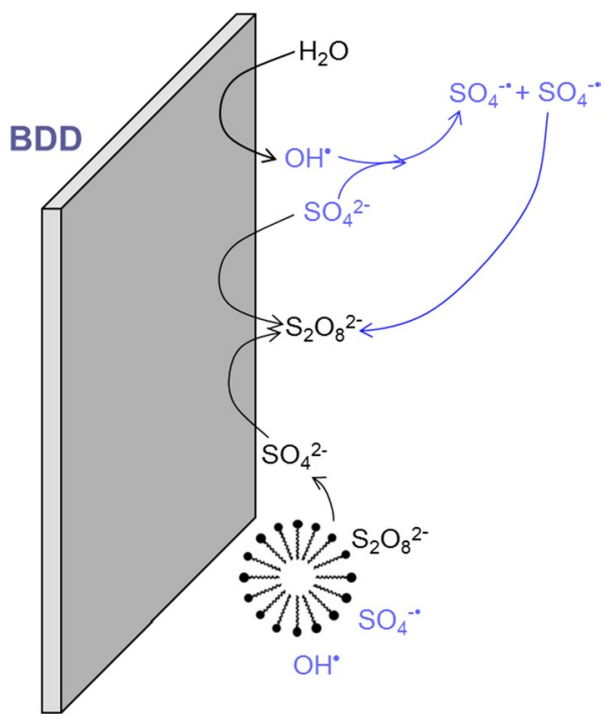

Fig. 4 Mechanism proposal of the electrochemical production of persulfate with boron-doped diamond (BDD) electrode by oxidizing sulfate in solution and sulfate released by surfactant after its degradation

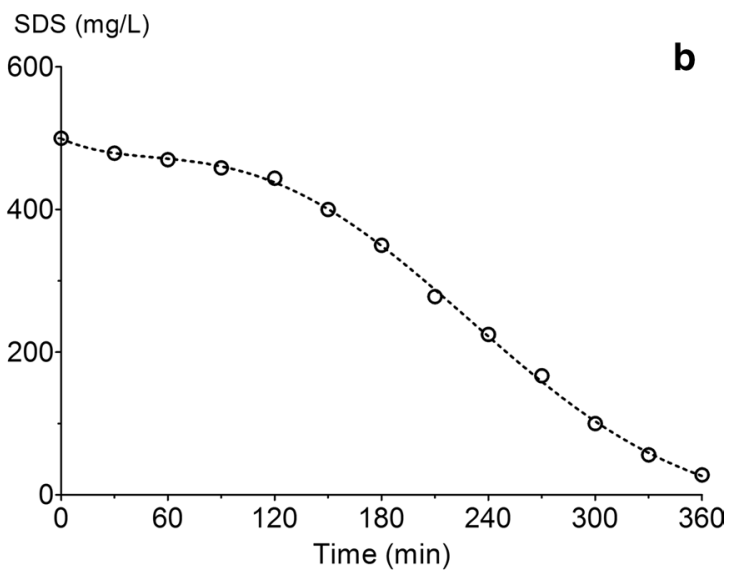

applied current densities (a) and at $60 \mathrm{~mA} \mathrm{~cm}^{-2}$ (b). Chemical oxygen demand (COD) and sodium dodecyl sulfate (SDS) 
in the presence of sodium dodecyl sulfate, for this reason, more experiments as well as a mass balance are necessary. However, these findings open new applications of sodium dodecyl sulfate for remediation because it improves the yield of $\mathrm{S}_{2} \mathrm{O}_{8}^{2-}$ under certain conditions with boron-doped diamond electrolysis. It can be consider as auxiliary reagent to depollute effluents, for example, with higher amount of oil or petroleum because emulsions can be formed to separate pollutants from water, and after that, these dispersed systems can be electrochemically treated.

Acknowledgments Financial support from National Council for Scientific and Technological Development (CNPq-465571/2014-0; 446846/2014-7 and 401519/2014-7) and Fundação de Amparo à Pesquisa do Estado de São Paulo-FAPESP (2014/50945-4) is gratefully acknowledged.

\section{References}

Araújo DM, Sáez C, Martinez-Huitle CA, Canizares P, Rodrigo MA (2015) Influence of mediated processes on the removal of Rhodamine with conductive-diamond electrochemical oxidation. Appl Catal B Environ 166-167:454-459. https://doi.org/10.1016/j.apca tb.2014.11.038

Bandala ER, Pelaez MA, Dionysios DD, Gelover G, Garcia AJ, Macías D (2007) Degradation of 2,4-dichlorophenoxyacetic acid (2,4-D) using cobalt-peroxymonosulfate in Fenton-like process. J Photochem Photobiol A Chem 186:357-363. https://doi.org/10.1016 /j.jphotochem.2006.09.005

Barreto JPP, Araújo KCF, Araújo DM, Martínez-Huitle CA (2015) Effect of $\mathrm{sp} 3 / \mathrm{sp} 2$ ratio on boron doped diamond films for producing persulfate. ECS Electrochem Lett 4:E9-E11. https://doi. org/10.1149/2.0061512eel

Brillas E, Martínez-Huitle CA (2015) Decontamination of wastewaters containing synthetic organic dyes by electrochemical methods. An updated review. Appl Catal B Environ 166-167:603. https://doi. org/10.1016/j.apcatb.2014.11.016

Budaev SL, Batoeva AA, Tsybikova BA (2015) Degradation of thiocyanate in aqueous solution by persulfate activated ferric ion. Miner Eng 8:88-95. https://doi.org/10.1016/j.mineng.2015.07.010

Cañizares P, Saéz C, Sánchez-Carretero A, Rodrigo MA (2008) Influence of the characteristics of p-Si BDD anodes on the efficiency of peroxodiphosphate electrosynthesis process. Electrochem Commun 10:602-606. https://doi.org/10.1016/j.elecom.2008.01.038
Chen WS, Su YC (2012) Removal of dinitrotoluenes in wastewater by sono-activated persulfate. Ultrason Sonochem 19:921-927. http s://doi.org/10.1016/j.ultsonch.2011.12.012

Davis J, Baygents JC, Farrell J (2014) Understanding persulfate production at boron doped diamond film anodes. Electrochim Acta 150:68-74. https://doi.org/10.1016/j.electacta.2014.10.104

Fan G, Cang L, Gomes HI, Zhou D (2015) Electrokinetic delivery of persulfate to remediate PCBs polluted soils: effect of different activation methods. Chemosphere 144:138-147. https://doi. org/10.1016/j.chemosphere.2015.08.074

Holmberg K, Jönsson B, Kronberg B, Lindman B (2002) Surfactants and polymers in aqueous solution, Secound edn. Wiley, England. ISBN 978-0-471-49883-4

Jurado E, Fernández-Serrano M, Núñez-Olea J, Luzón G, Lechuga M (2006) Simplified spectrophotometric method using methylene blue for determining anionic surfactants: applications to the study of primary biodegradation in aerobic screening test. Chemosphere 65:278-285. https://doi.org/10.1016/j.chemosphere.2006.02.044

Liang C, Huang CF, Mohanty N, Kurakalva RM (2008) A rapid spectrophotometric determination of persulfate anion in ISCO. Chemosphere 73:1540-1543. https://doi.org/10.1016/j.chemosph ere.2008.08.043

Maniasso N (2001) Ambientes micelares em química analítica. Quím Nova 24:87-93. https://doi.org/10.1590/S0100-404220010001 00015

Michaud PA, Mahe E, Haenni W, Perret A, Comninellis C (2000) Preparation of peroxodisulfuric acid using boron-doped diamond thin film electrodes. Electrochem Solid State Lett 3:77-79. http s://doi.org/10.1149/1.1390963

Santos EV, Sáez C, Martinez-Huitle CA, Cañizares P, Rodrigo MA (2015a) Combined soil washing and CDEO for the removal of atrazine from soils. J Hazard Mater 300:129-134. https://doi. org/10.1016/j.jhazmat.2015.06.064

Santos EV, Sáez C, Martinez-Huitle CA, Canizares P, Rodrigo MA (2015b) The role of particle size on the conductive diamond electrochemical oxidation of soil-washing effluent polluted with atrazine. Electrochem Commun 55:26-29. https://doi.org/10.1016 /j.elecom.2015.03.003

Serrano K, Michaud P, Michaud C, Savall A (2002) Electrochemical preparation of peroxodisulfuric acid using boron doped diamond thin film electrodes. Electrochim Acta 48:431-436. https://doi. org/10.1016/S0013-4686(02)00688-6

Xie P, Ma J, Liu W, Zou J, Yue S, Wiesner MR, Fang J (2014) Removal of 2-MIB and geosmin using UV/persulfate: contributions of hydroxyl and sulfate radicals. Water Res 69:223-233. https://doi. org/10.1016/j.watres.2014.11.029 